\title{
Packaging Design, Weld Fatigue analysis and Validation of Diesel Exhaust After-treatment System
}

\author{
Sonal Nareddiwar ${ }^{1}$, Tapobrata Dey ${ }^{1} \&$ R. Sunilkumar ${ }^{2}$ \\ ${ }^{1}$ Department of Mechanical Engineering, D Y Patil College of Engineering, Akurdi, 411044, Savitribai Phule Pune \\ University, India \\ ${ }^{2}$ Cummins Technologies India Ltd., Pune, India \\ Correspondence: Tapobrata Dey, Department of Mechanical Engineering, D Y Patil College of Engineering, Akurdi, \\ 411044, Savitribai Phule Pune University, India. E-mail: tapobrata.dey@gmail.com
}

Received: August 9, 2018

Accepted: October 26, 2018

Online Published: November 30, 2018

doi:10.5539/mer.v8n2p36

URL: https://doi.org/10.5539/mer.v8n2p36

\begin{abstract}
Diesel exhaust after treatment system is usually designed to meet stringent packaging constraints and emission norms. After treatment packaging has critical impact on the overall system efficiency and durability since many components in exhaust systems have welded joints. An after treatment inlet and outlet tube joints, connected to engine outlet and Original Equipment Manufacturer (OEM) tailpipe respectively are subjected to vibrations and bending moment leading to fatigue failure at the inlet/outlet welded joints. It has been observed over the years that the prevailing failure modes in after treatment systems are cracked welds at joints between inlet tubes and flanges, outlet tubes and connecting tailpipes. Fatigue failure is a complex and progressive form of local damage which occurs in welded components of exhaust after-treatment systems. Thus, this fatigue failure needs to be estimated accurately and at the early stage of design to save cost and time. But due to geometrical irregularities, compact packaging design and load transfer conditions, it becomes difficult to estimate accurate fatigue strength of the welded areas. Thus weld fatigue analysis, a high cycle fatigue test to validate inlet/outlet module of exhaust system against dynamic overturning bending moment and to calculate the location of minimum weld fatigue life within the inlet welded joints is performed. Weld fatigue analysis uses advanced fatigue assessment technique, BS 7608, Stress x Life (S x N) approach for accurate and precise estimation of welds. The present work deals with reducing the package volume of the after treatment system by applying different concepts, verifying design robustness by FEA simulation using ANSYS 18.2 and validating the structural durability of the system by testing. The objective of the present work is to estimate the fatigue life of the welded structures precisely and accurately, calculate the threshold bending moment to determine whether the design is robust to the bending moment loads seen over course of its life and make design modifications as per simulation result. Further the FEA and testing results of weld fatigue analysis are correlated.
\end{abstract}

Keywords: Fatigue Analysis, After-treatment system, Fatigue life, Stress-based approach, packaging design

\section{Introduction}

The diesel engine has the merits of high power output, low fuel consumption and excellent longevity. However, the fuel lean combustion also generates significant amount of hazard emissions, such as oxides of nitrogen and particle matters, exposure of which increases the risk of respiratory infection, heart problems, premature death and lung cancer.

\section{Design Procedure}

Hence regulation on diesel engine emission has become more and more stringent, leading to a large volume of diesel aftertreatment catalysts. Catalyst packaging becomes a challenging task for diesel aftertreament system design. The criteria for an optimal packaging design are to: (1) fit large catalysts into the limited space of the vehicles, and (2) maintain the well utilization of packed catalysts. As emission regulations are getting stringent day by day, it is also leading to lighter and compact vehicles. The after treatment system is designed to be mounted either on engine or on chassis. Also while designing an after treatment system, it is needed to check the available space according to the mounting strategy. As per OEM space claim requirement, different concepts for compact packaging design are generated during brain storming sessions with the cross functional team. Using Pugh matrix, one best concept for 
compact packaging is down selected and preliminary CAD models are created using Creo 2.0. The preliminary CAD model for newly selected concept design is shown as in Figure 1.

After designing, OEM fit check is done to verify whether the system fits properly in the vehicle without any interference with the surrounding parts and keeping in mind the serviceability concern. The design has passed in OEM fit check on the basis of feedback from OEM. There is considerable length reduction in the new concept design as compared to baseline design. The overall system length has been reduced by $12 \%$.

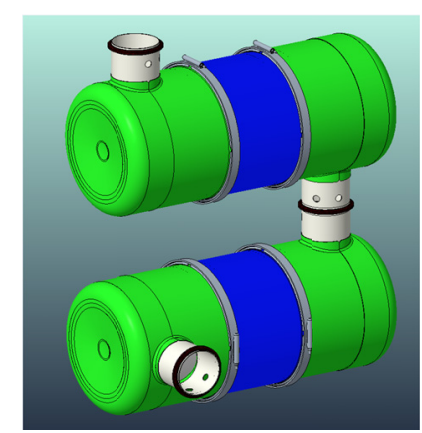

Figure 1. Preliminary CAD model for concept design

\section{Weld Stress and Fatigue Life Assessment- BS7608 Approach}

Thin stainless steel components with high heat resistance, high corrosion resistance and excellent workability are increasingly used in exhaust systems. Because exhaust systems are usually welded structures, more emphasis is on strength improvement and characteristics and mechanism involved in welded joints (Oh, 2017). Fatigue is one of the most critical failure mode occurring in the welded structures. Thus fatigue life assessment is the critical step for analyzing vehicle's structural durability. However welded joints are the weakest part of the exhaust system. In assessing fatigue life of welded components, a reliable determination of fluctuating stress is required (Alexandre et al., 2001). The stress concentration in welded joints dominates the fatigue behavior of welded structure. The stress distribution in welded joints primarily depends on geometry, stress concentration, loading case and material elastic or plastic behavior (Apurva \& Pande, 2014).

Structural stress methods are now widely used in fatigue life assessment of welded structures and structures with stress concentrations. The structural stress concept is based on the assumption of a global stress distribution at critical locations such as weld toes or weld throats, and there are several variants of structural stress approaches available (Wei, Yang, \& Luo, 2014).

For analyzing the welded structures and for fatigue life estimation of welds, many reliable and validated fatigue life assessment approaches are currently implemented.

The fatigue strength of welded joints in steels structures is defined by the British Standards 7608. In BS 7608, welds are classified into several groups and for each group the characteristic stress- life curves are defined for various probabilities of failure. The figure 1 shows the S-N curve defined for various classes of welded joints.

The curves have a constant slope between $10^{5}$ and $10^{7}$ cycles, where the stress-life relationship is defined by the equation (for the mean life of welded structure):

$$
N=\frac{K_{o} \Delta^{d}}{S^{m}}
$$

Where,

$\mathrm{N}$ is the endurance in cycles.

$\mathrm{S}$ is the nominal stress range.

Ko is the constant for a particular weld classification

$\mathrm{m}$ is the slope of the S-N curve in log-log scale.

$\Delta$ is a function of the standard deviation of the fatigue life

$d$ is number of standard deviations from the mean 
The variable $d$ is termed as "design criterion" and is expressed as number of standard deviations from the mean life. BS approach assumes ' $d$ ' as a positive if it is below the mean line (BS7608, 1993).

To account for variability the weld fatigue curves given in various weld fatigue methods are provided with an associated probability of failure. The stress-life (SN) curves in BS7608 are defined by standard deviations away from the mean value. Figure 2 shows weld fatigue curves for a specific weld class with varied probabilities of survival (BS7608, 1993).

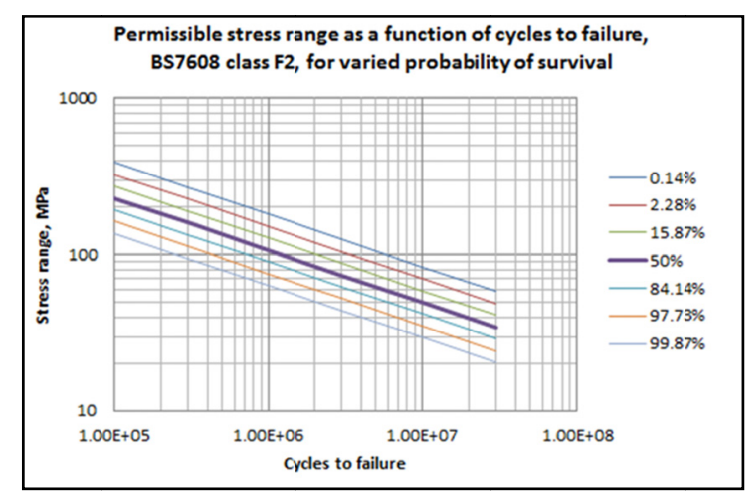

Figure 2. S-N curves for Weld Fatigue from BS 7608 for various Probabilities of Failure (BS7608, 1993)

In the present work, fatigue design and evaluation of welded joints are primarily carried out based on structural stress with a series of classified weld S-N curves due to capability of consistently capturing the stress concentration effects on fatigue behaviour and their mesh insensitivity in stress determination at welds.

\section{Weld Fatigue Analysis approach}

Weld fatigue analysis is a high cycle fatigue test is used to validate after treatment module inlets and outlets against dynamic overturning bending moment. This analysis is used to evaluate life of weld in terms of life cycles. The resulting structural stress calculations will be mesh-insensitive, regardless of element size, element type, integration order used, as long as the overall geometry of a component is reasonably represented in a finite element model. Weld fatigue analysis is important because weld strength determines the assembly strength and also tolerable stress amplitude in weld HAZ is very less as compared to ultimate tensile strength of the parent material. Finite element model of the welded body is built to match the loading and constraint conditions of the physical tests, and then tested to simulate the physical testing. A static analysis is run on each finite element model to determine the stresses present within the structure.

These stresses are then transformed into the equivalent structural stress range and are fed as input in Fe-Safe which further calculates the weld fatigue life based on Master S-N curve.

- $\quad$ Required Inputs:

The primary input for weld fatigue analysis is moment magnitude, number of cycles, permissible probability failure along with CAD models, liners material properties and boundary conditions.

Moment Magnitude $=320 \mathrm{Nm}$

Number of cycles $=1$ million

Permissible probability of failure $=2.2 \%$

- Acceptance criteria:

The passing criterion for acceptable and safe design is 1 e 6 cycles at $2.2 \%$ probability of failure.

- Analysis assumptions:

a) In Fe-safe, fatigue life calculations are done by considering steel material properties of weld class F2 using BS7608 approach with $\mathrm{d}=2$ ( $2.2 \%$ of probability of failure).

b) Temperature effects are not considered in the simulation

c) Slip and separation between parts is assumed not to occur, justifying a linear model.

d) The effect of residual stress due to forming will have little effect on mean stress. 
e) Variation in thickness during forming operation is neglected.

f) Stress concentrations due to welded bosses and forces from the acceleration of wire, straps, and insulation have a negligible effect on damage.

g) Sensor bosses are not welded in FE model. Bosses share bonded contact with parent bodies.

- Importing CAD geometry and Solid to shell conversion:

In Fatigue analysis, inlet/outlet tube CAD model is imported and converted into shell body by assigning appropriate thickness and extracting mid surfaces. The concerned welded areas whose fatigue life needs to be evaluated are modelled using 4-node shell elements. The nodes of the shell elements representing the weld are offset (by $t / 2$ ) from the location of the weld toes. Figure 3 shows the CAD geometry of inlet tube assembly.

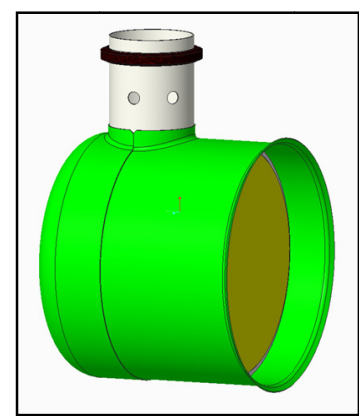

Figure 3. CAD geometry of inlet/outlet sub-module

- Weld details:

Fatigue analyses of weldments require detailed knowledge of the stress fields in critical regions. From the weld drawings, the details of different welded areas are sought and accordingly different shell bodies are connected by welds. The weld between inlet tube and surrounding components are modeled by using vertical and inclined areas.

Figure 4 and Table I shows the weld details of inlet/outlet tube joint.

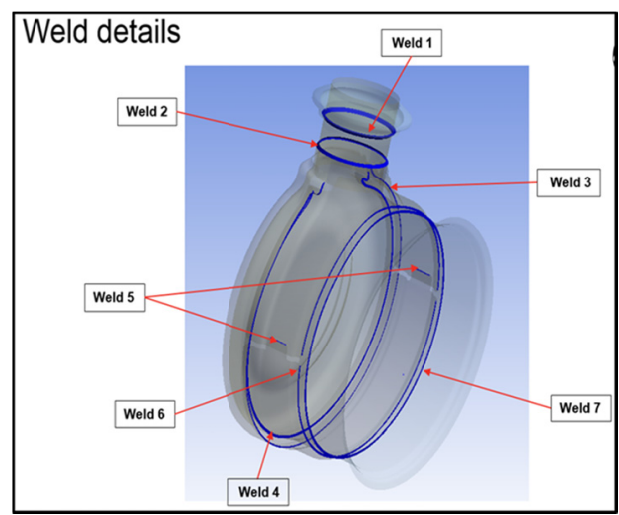

Figure 4. Weld details of the inlet tube sub-module

Table I. Weld Details of Inlet Tube Joint

\begin{tabular}{cc}
\hline Weld Location & Weld Name \\
\hline Weld-1 & Weld between inlet tube and Marmon \\
Weld-2 & Weld between inlet tube and inlet flanges \\
Weld-3 & Weld between heat shields at inlet \\
Weld-4 & Weld between flanges at inlet \\
Weld-5 & Weld between Heat shields \\
Weld-6 & Weld between inlet $2^{\text {nd }}$ flange and $2^{\text {nd }}$ heat shield \\
Weld-7 & Weld between inlet $2^{\text {nd }}$ flange and outer body \\
\hline
\end{tabular}


- Meshing:

In Fatigue analysis, in the critical areas such as welded areas, very fine mesh of quad elements is used. Also quad elements are less stiff and give realistic and accurate results. Shell 181 elements are used for meshing. Figure 5 and Table II shows the meshing details.

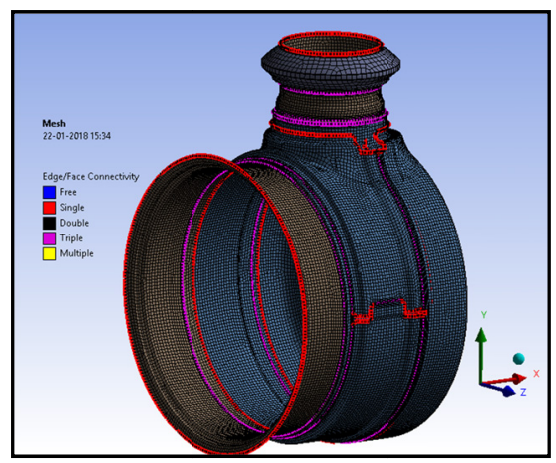

Figure 5. Meshed inlet tube sub-module

Table II. Discretization details

\begin{tabular}{cccc}
\hline Element Size & Element type & No. of Nodes & No. of Elements \\
\hline $3 \mathrm{~mm}$ & Quad4 & 107263 & 131073 \\
& Shell 181 & & \\
\hline
\end{tabular}

- Defining Contacts:

Contacts are defined so that the bodies stay in load transfer path and offers realistic force distribution. Among different contact types, bonded contacts and No-separation contacts are of linear types which are used for connecting various bodies because that allows for rigid force transfer. Figure 6 shows the contact details.

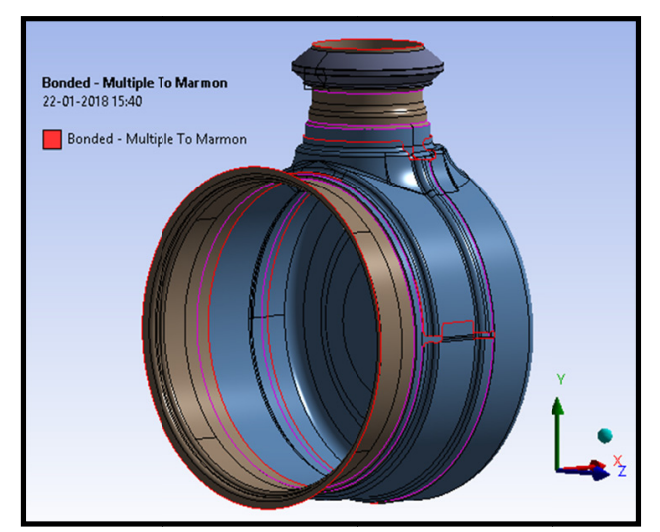

Figure 6. Contact details

- Assigning Material Properties:

It is assumed that the inlet/outlet sub-module and all other parts both are manufactured from SS409. Both the parent and weld material are assumed to be SS409 and properties are listed in Table III.

Table III: Material Properties

\begin{tabular}{cc}
\hline \multicolumn{2}{c}{ Component Frame - Material SS409 } \\
\hline Elastic Modulus, E (MPa) & $2.06 \mathrm{e}+5$ \\
Density, $\mathrm{g}\left(\mathrm{kg} / \mathrm{m}^{\wedge} 3\right)$ & 7750 \\
Yield Strength, $(\mathrm{MPa})$ & 240 \\
Poisson's ratio & 0.28 \\
\hline
\end{tabular}


- Application of Loads and Boundary conditions:

2 load step approach: Multi-axial stress is always present in the welded component with or without complex geometrical configurations. Thus, the multi-axial effect on fatigue life should be considered properly. In order to investigate the influence of the loads, two loading cases are considered: axial tension load and out of plane bending moment. The first step in the Weld fatigue analysis is creating two load steps in ANSYS, corresponding to two orthogonal input loadings $1 \mathrm{~m}$ out from the weld plane. The stress fields from these static solutions will be linearly superposed in Fe-safe to simulate the loading of each element over the weld surface throughout the entire loading cycle.

Fixed Supports: In Weld fatigue analysis, fixed supports are applied at $45^{\circ}$ on the top and bottom sides of the outer body of the inlet subassembly to simulate the forces exerted by fixture at the time of testing. The fixed supports are applied to constrain the exerting forces and fix the model to avoid deformation at that location as shown in Fig 7.

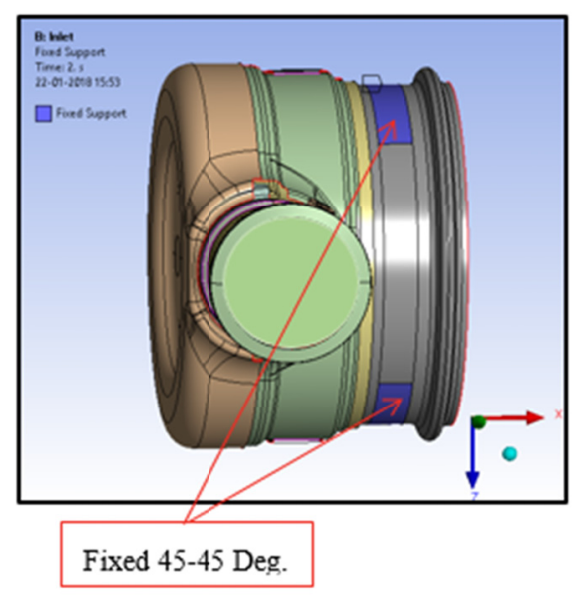

Figure 7. Application of Fixed supports

Remote force: Also a remote force of $320 \mathrm{~N}$ is applied at $1000 \mathrm{~mm}$ distance to create moment on the inlet tube as shown in Fig 8. Remote force is considered to be rigid because of the rigid connections.

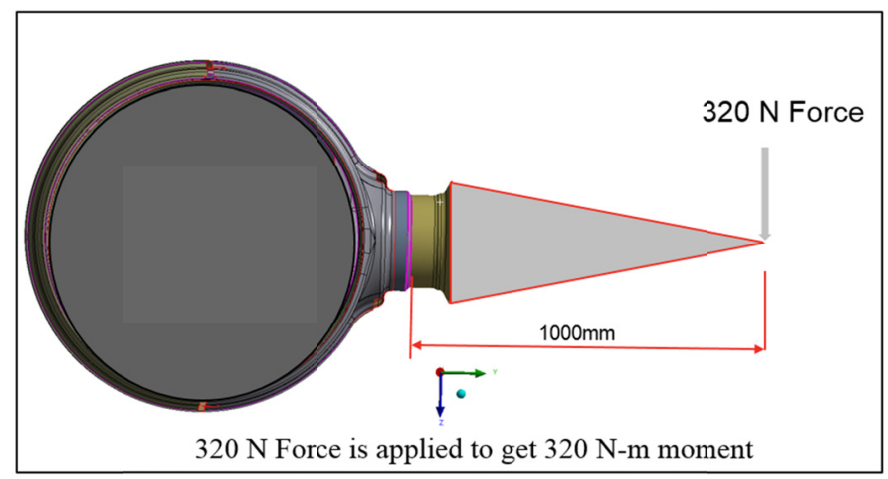

Figure 8. Application of Remote force

\section{Simulation Results}

The FEA results for the $1^{\text {st }}$ iteration are shown in Table IV. 
Table IV. FEA RESULTS FOR 1st ITERATION

\begin{tabular}{ccc}
\hline Weld Location & Weld Name & No. of life cycles with 2.2 \% probability of failure (d=2) \\
\hline Weld-1 & Weld between inlet tube and Marmon & $2.5 \mathrm{E}+06$ \\
Weld-2 & Weld between inlet tube and inlet flanges & $7.20 \mathrm{E}+05$ \\
Weld-3 & Weld between heat shields at inlet & $6.04 \mathrm{E}+06$ \\
Weld-4 & Weld between flanges at inlet & $2.51 \mathrm{E}+06$ \\
Weld-5 & Weld between Heat shields & $1.2 \mathrm{E}+06$ \\
Weld-6 & Weld between inlet 2 ${ }^{\text {nd }}$ flange and $2^{\text {nd }}$ heat shield & $2.27 \mathrm{E}+06$ \\
Weld-7 & Weld between inlet $2^{\text {nd }}$ flange and outer body & $1.64 \mathrm{E}+06$ \\
\hline
\end{tabular}

Since weld 2 fails in $1^{\text {st }}$ iteration, several design modifications were done and analysis was run until the weld passes the acceptance criteria.

The Table V shows the $6^{\text {th }}$ iteration with design modifications passing the acceptance criteria.

Table V. Fea results for 6th iteration

\begin{tabular}{|c|c|c|}
\hline Weld Location & Weld Name & No. of life cycles with $2.2 \%$ probability of failure $(\mathrm{d}=2)$ \\
\hline Weld-1 & Weld between inlet tube and Marmon & $3.17 \mathrm{E}+06$ \\
\hline Weld-2 & Weld between inlet tube and inlet flanges & $1.18 \mathrm{E}+06$ \\
\hline Weld-3 & Weld between heat shields at inlet & $5.12 \mathrm{E}+06$ \\
\hline Weld-4 & Weld between flanges at inlet & $2.87 \quad \mathrm{E}+06$ \\
\hline Weld-5 & Weld between Heat shields & $1.2 \mathrm{E}+06$ \\
\hline Weld-6 & Weld between inlet $2^{\text {nd }}$ flange and $2^{\text {nd }}$ heat shield & $2.07 \quad \mathrm{E}+06$ \\
\hline Weld-7 & Weld between inlet $2^{\text {nd }}$ flange and outer body & $1.64 \mathrm{E}+06$ \\
\hline
\end{tabular}

- Design modifications:

Remove skip weld and apply full weld at weld 2 and also the tube length is increased by $6 \%$. If the tube length is increased further, the weld fails.

Thus, good to go with the iteration 6 design.

- M-N curve plot:

Static analysis results are read in Fe-safe for fatigue life calculation using BS 7608 approach.

The output outlined in this paper is a plot of stress 'normal to the weld toe' over the course of a single loading cycle created by Fe-safe. This reveals the peak to peak stress range experienced by a weld. The bending moment versus its respective number of fatigue life cycles is plotted in the Fig 9 as M-N curve which is further used to calculate threshold bending moment.

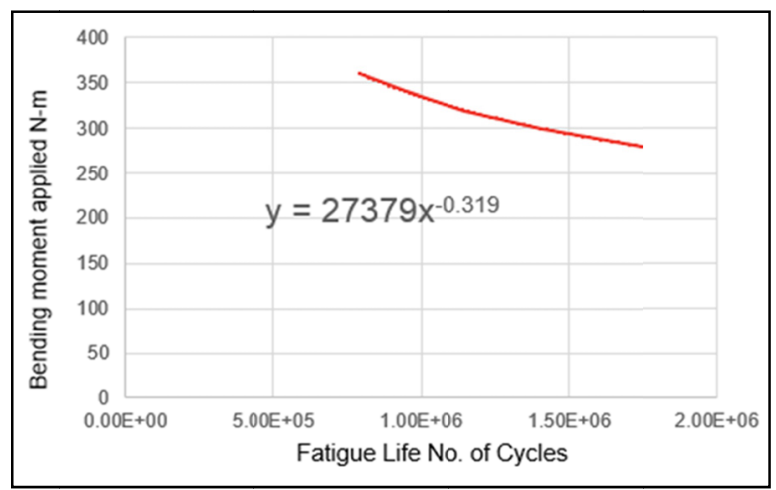

Figure 9. M-N Curve for Inlet sub-Module 
- Calculation of threshold bending moment:

Threshold bending moment is the moment applied to get the maximum fatigue life cycles during the service life of the component.

Bending moment required for 1 million life cycles of inlet tube $=27379 \times\left((1000000)^{(-0.319)}\right)$

$=333.74 \mathrm{Nm}$

$333.74 \mathrm{Nm}$ bending moment is to be applied to get 1 Million life cycles.

- $\quad$ Fatigue life plots of various critical welds at inlet tube joint:

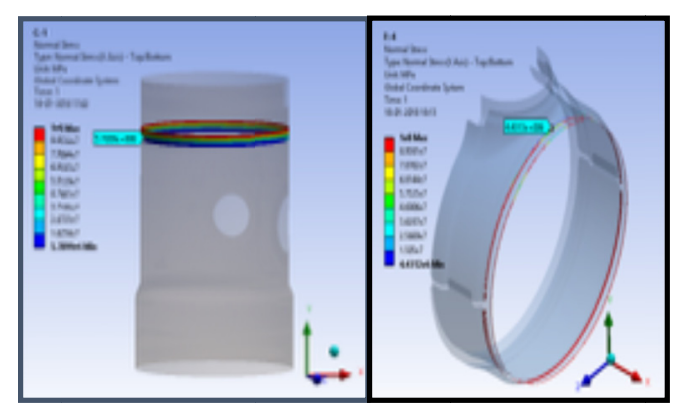

(a)

(b)

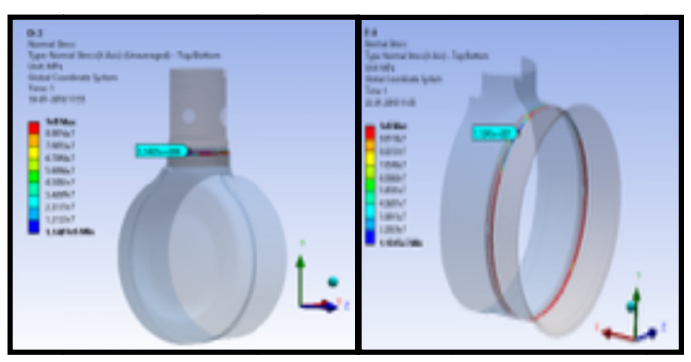

(c)

(d)

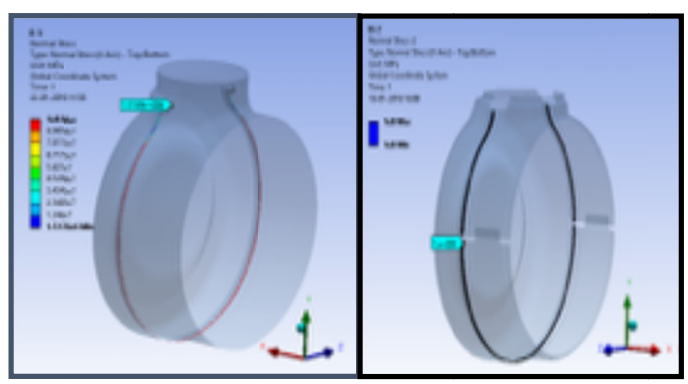

(e)

(f)

Figure 10. Fatigue Life plots for all weld locations at inlet

Fig 10 shows the fatigue life plots for the welded joints in inlet sub module. All welds passes the acceptance criteria of 1 E06 life cycles.

Fatigue life plots for all welded joints in the inlet sub module are shown in Fig 10 and summarized in Table V. All the welded joints of the current inlet tube design have fatigue life more than 1 million life cycles. Among all these joints, the most critical and prone to failure joints are weld 2, at inlet tube and flange having fatigue life 1.18 million and weld between heat shield and flange having fatigue life 1.2 million meet the acceptance criteria of 1 million life cycles. Also these simulation results infer that with $97.8 \%$ confidence interval $(\mathrm{d}=2)$, all the welds will survive more than 2 million life cycles without failure. The probability of three samples surviving 1.2 million life cycles during test is $100 \%$. Thus as per FEA results, inlet tube design has safe fatigue life and is structurally durable and robust to $333.74 \mathrm{Nm}$ bending moment. 


\section{Validation of Weld Fatigue Analysis}

This is the standard test method used to verify that the inlet or outlet welded tube joints of an aftertreatment device have adequate high cycle fatigue strength. Thus, the main purpose of this test is to determine adequate high-cycle fatigue life of aftertreatment inlet/outlet welded tube joints. The outcome of this test will be failure modes that include but are not limited to leakage from within the tested inlet/outlet joint and internal cracks. The part needs to be manufactured using appropriate production process. These samples are then subjected to a loading that applies a $360^{\circ}$ strain to produce high fatigue failure. Figure 11 shows the test setup for Weld Fatigue Analysis.

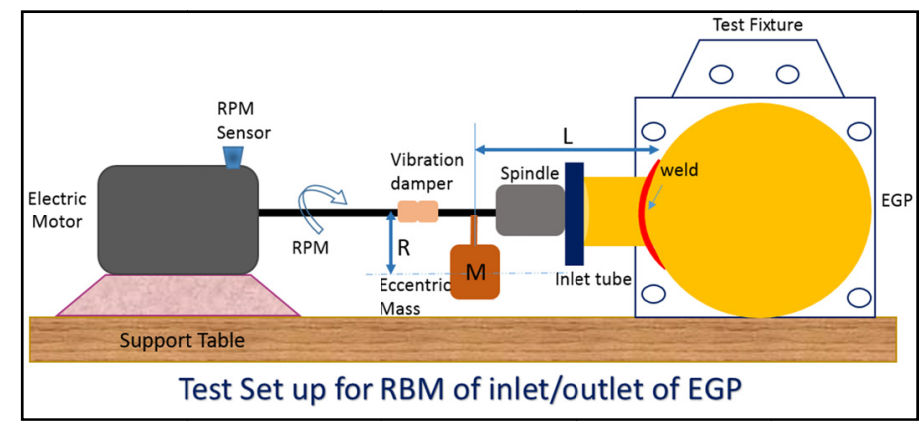

Figure 11. Test setup for Weld Fatigue Analysis of Inlet/Outlet of EGP

- Test Procedure:

In order to determine the fatigue strength of a welded joint configuration under a given load condition, it is necessary to test a series of similar specimens. Each of the specimens is subjected to constant amplitude loading and the number of loading cycles required to produce failure in each specimen is recorded. An after treatment system is completed painted white and all the welded joints are marked red in order to detect any deformation or cracks formed during testing. The after treatment device is then installed on the Rotating bending test machine with the guillotine clamps. The bending moment load of $320 \mathrm{~N}$ is applied with an eccentric mass which is connected to the electric motor by a rotating shaft. A spindle is attached to the inlet/outlet joint of an after treatment device and transfers a moment load from a spinning mass. Due to this, both rotating and bending forces are applied at the inlet tube. A vibration damper is located between the motor and the spindle that reduces vibration load from the motor into after treatment device. Before starting the test, an exhaust inlet sub module is inspected for any leakages or cracks. Test software is setup and test is started. Post-test inspection is conducted and test report is created.

RPM is needed to be calculated to run at the bending moment specified by the given formula,

$$
R P M=\frac{60}{2 \pi} \sqrt{\frac{M b}{L * m * R}}
$$

Where,

$\mathrm{m}$ is the weight of Rotating mass

$\mathrm{L}$ is the moment arm length from center of mass to first weld toe

$\mathrm{Mb}$ is the bending moment applied

$\mathrm{R}$ is the radius of the rotating mass

\section{Validation Results}

The objective of this test is to validate the inlet design is robust to the bending moment loads seen over course of its life on the On and Off-Hwy applications. The after treatment body joint components were tested for high-cycle fatigue life according to Company's standard test procedure. The components were tested against the recommended test parameters for On- Highway and Off-Highway applications. A fair amount of components passed the test and exceeded the 1.2 million cycle. Again the samples were leak tested and inspected and continued onto 2 million cycles without issue.

The test results are shown as follows: 


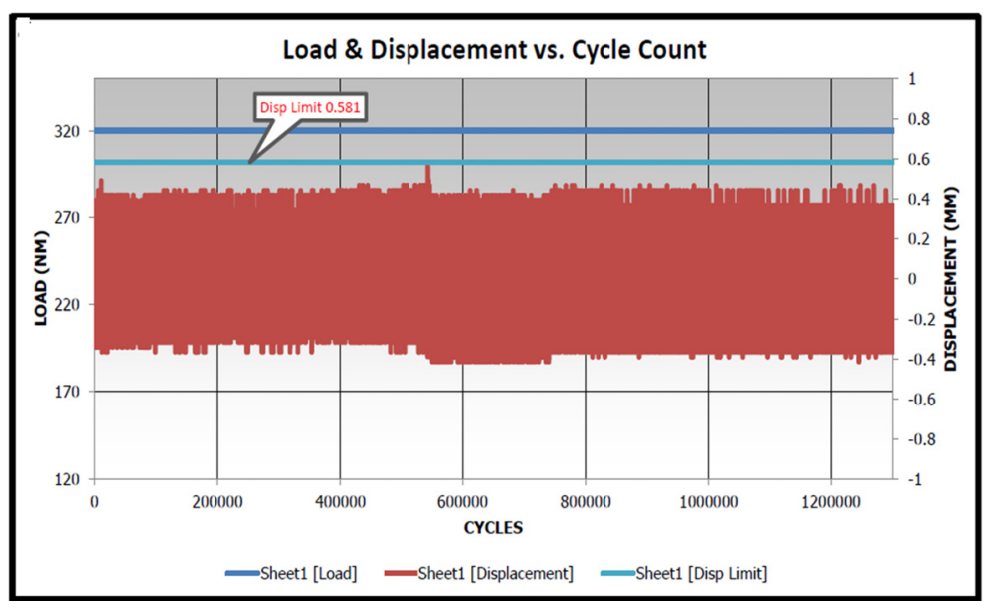

Figure 12. Test data for sample-1

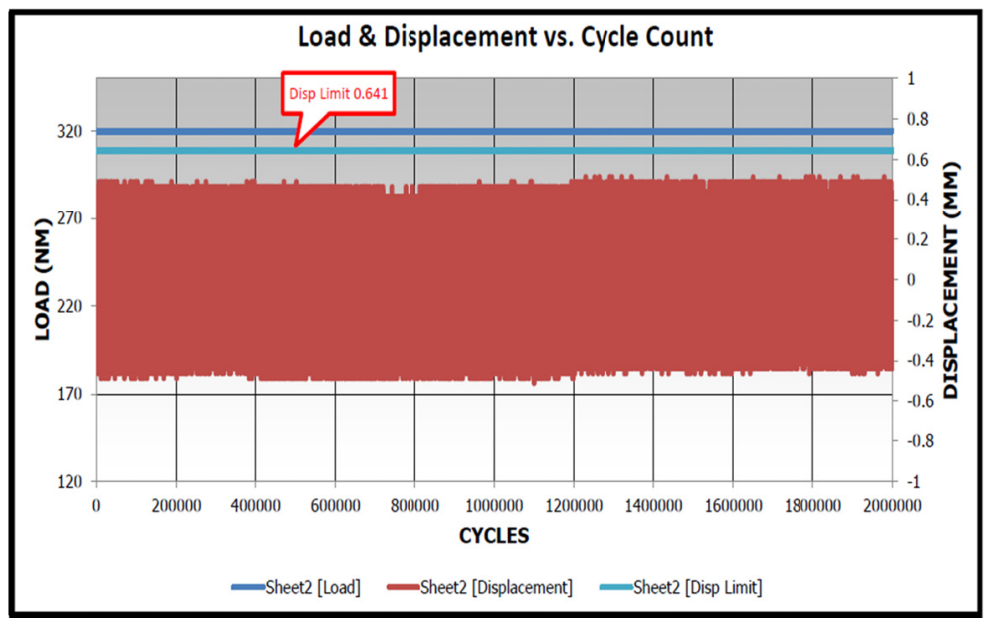

Figure 13. Test data for sample-2

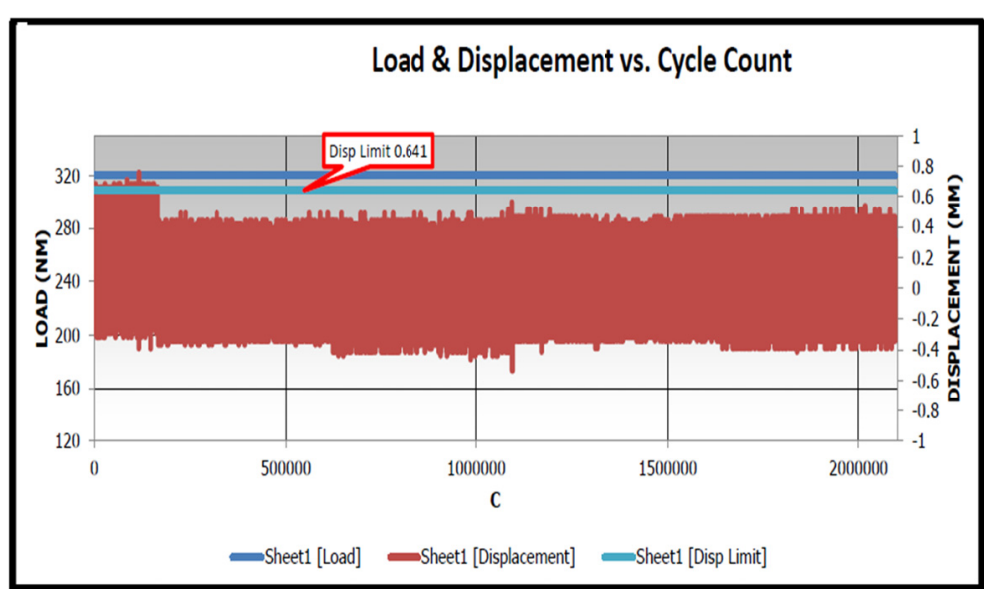

Figure 14. Test data for sample-3

All three test samples completed the 2.0 million test cycles at $320 \mathrm{~N}$-m of test bending load with no abnormal jerks or vibrations and showed no internal and external visible weld fatigue crack in the Inlet section of the aftertreatment system during post inspection.

The correlation of fatigue analysis of both by simulation and validation is shown in Table VI. The correlation between simulation and validation results shows that design is robust and have safe fatigue life. 
Table VI. Correlation of simulation and validation

\begin{tabular}{|c|c|c|c|}
\hline Weld Location & Weld Name & Simulation Results & Validation Results \\
\hline Weld-1 & Weld between inlet tube and Marmon & $3.17 \mathrm{E}+06$ & $2.0 \mathrm{E}+06$ \\
\hline Weld-2 & Weld between inlet tube and inlet flanges & $1.18 \mathrm{E}+06$ & $2.0 \quad \mathrm{E}+06$ \\
\hline Weld-3 & Weld between heat shields at inlet & $5.12 \mathrm{E}+06$ & $2.0 \mathrm{E}+06$ \\
\hline Weld-4 & Weld between flanges at inlet & $2.87 \quad \mathrm{E}+06$ & $2.0 \mathrm{E}+06$ \\
\hline Weld-5 & Weld between Heat shields & $1.2 \mathrm{E}+06$ & $2.0 \quad \mathrm{E}+06$ \\
\hline Weld-6 & Weld between inlet $2^{\text {nd }}$ flange and $2^{\text {nd }}$ heat shield & $2.07 \quad \mathrm{E}+06$ & $2.0 \mathrm{E}+06$ \\
\hline Weld-7 & Weld between inlet $2^{\text {nd }}$ flange and outer body & $1.64 \mathrm{E}+06$ & $2.0 \quad \mathrm{E}+06$ \\
\hline
\end{tabular}

\section{Conclusion}

The down selected concept for compact packaging design of after treatment system shows considerable length reduction by $12 \%$ as compared to baseline design.

The FEA results also states that with $97.8 \%$ confidence interval $(\mathrm{d}=2)$, all the welds will survive more than 1 million life cycles without failure with the design modification in tube length.

It is also ensured about validation through FEA analysis of welds that the probability of three samples surviving 1.2 million life cycles during test is $100 \%$.

It is also inferred from the fatigue simulation that $333.74 \mathrm{~N}-\mathrm{m}$ threshold bending moment is to be applied to achieve maximum service life of the inlet components.

The validation results infer that all the three test samples have passed the safe design criteria of 1.2 million life cycles without any cracks or failure.

The correlation of Weld fatigue simulation and testing have $2 \%$ variation in both the results considering number of life cycles.

Thus as per FEA results and testing, inlet tube design has safe fatigue life (reduced warranty claims) and is structurally durable and robust.

\section{Acknowledgment}

I express my sincere gratitude towards the faculty members. I am also thankful to Cummins India Ltd. for sponsoring and supporting in my project.

\section{References}

Oh, G. (2017). Bending Fatigue Strength and the Effect of Assembling Stress on Fillet Welded Joints of Catalyst Muffler Flange Pipes. International Journal of Automotive Engineering, 8(2), 87-94.

Alexandre, S. F., Camarão, A. F., Fernandes, A. D. O., Bezerra, M. A., Argentino, M. A., \& Ripoli, R. R. (2001). A Finite Element Approach for Fatigue Analysis of Welded Components (No. 2001-01-4077). SAE Technical Paper.

Apurva, A., \& Pande, D. (2014). Mesh Insensitive Structural Stress Approach for Welded Components Modelled using Shell Mesh. International Journal of Engineering Research \& Technology, 3(11), 1425-1434.

Wei, Z., Yang, F., \& Luo, L. (2012). Fatigue life Assessment of Welded Structures with the Linear Traction Stress Analysis Approach. SAE international Journal of Material Manufacturing, 5(1), 183-193.

Code of practice for Fatigue design and assessment of steel structures, British standard, BS7608, 1993.

Wei, Z., Hamilton, J., Yang, F., Luo, L., Lin, S., Kang, H., \& Dong, P. (2013). Comparison of Verity and Volvo Methods for Fatigue Life Assessment of Welded Structures (No. 2013-01-2357). SAE Technical Paper.

Kyuba, H., \& Dong, P. (2005). Equilibrium-equivalent structural stress approach to fatigue analysis of a rectangular hollow section joint. International Journal of Fatigue, 27(1), 85-94.

Kang, H. T., Dong, P., \& Hong, J. K. (2007). Fatigue analysis of spot welds using a mesh-insensitive structural stress approach. International Journal of fatigue, 29(8), 1546-1553.

Gao, Y., Chucas, D., Lewis, C., \& McGregor, I. J. (2001). Review of CAE fatigue analysis techniques for spot-welded high strength steel automotive structures (No. 2001-01-0835). SAE Technical Paper.

Stocco, D., Vilela, D., \& Batalha, G. F. (2009). Spot weld fatigue durability performance evaluation through the use of fea (No. 2009-36-0189). SAE Technical Paper. 
Zhang, S. (2001). Recent developments in analysis and testing of spot welds (No. 2001-01-0432). SAE Technical Paper.

\section{Copyrights}

Copyright for this article is retained by the author(s), with first publication rights granted to the journal.

This is an open-access article distributed under the terms and conditions of the Creative Commons Attribution license (http://creativecommons.org/licenses/by/4.0/). 